\title{
Some Comments on Parents Contacting with their Stillborn Baby
}

Sun JC and Sheu SJ

Department of Nursing, Chang Gung Institute of Technology, Taoyuan County, Taiwan

Department of Nursing, Institute of Community Health Care, National Yang-Ming University, Taipei, Taiwan

"Corresponding author: Sheu SJ, Department of Nursing, Institute of Community Health Care, National Yang-Ming University, Taipei, Taiwan, Tel: +886228267271; Email: sjsheu@ym.edu.tw

Received date: November 9, 2015; Accepted date: November 18, 2015; Published date: November 23, 2015

Copyright: (C) 2015 Sun JC, et al. This is an open-access article distributed under the terms of the Creative Commons Attribution License, which permits unrestricted use, distribution, and reproduction in any medium, provided the original author and source are credited.

\section{Introduction}

Stillbirth is recognized as one of the most traumatic experiences that a male or female parent needs to go through and may be associated with long-lasting and various extents of psychosocial effects. Parents might have had limited or no previous experience with fetal death and most of them are typically fearful and confused about what to expect and what options are available to them. Seeing and holding a live baby after birth is a parental normal response. Instead, research findings related to the practice of seeing and holding a stillborn baby is inconsistent and controversial.

The standards of psychosocial care has changed and its still evolving. Psychosocial care began to change from the late 1970s to the 1990 s in Sweden and the UK [1,2]. The guidelines recommend healthcare professionals to the grief of still born babies $[3,4,5]$. The UK guidelines recommend that they should avoid the stillborn baby death which will be great devastation to the Mother. It mainly aims that the mother of the infants should not be encouraged to see and hold the stillborn baby [4]. In fact, each parent's personal values, cultural traditions, and religious beliefs may deeply influence the amount of time spent with a deceased baby or occasionally preclude contact. Health professional should consider the parents' need to take their time with emotional processing, decision-making, and desired contact with their baby and provide culturally sensitive care in a manner that is intentional, unhurried, calm, and respectful.

We recommend that clinical care personnel accommodate parents' choices and cultural customs at grasping an appropriate time and place. Health professionals should better orient parents to the circumstances and assist in the additional decisions that parents may face in advance of the stillbirth. Parents should have sufficient time and information to consider the implications of seeing or not seeing their stillborn infant, express their feelings, share their experiences, and discuss what and how to do following the stillbirth [6,7]. Parent's feelings and decisions of whether or not to see and hold their stillborn infant should be respected and supported. With a better understanding of parent's belief systems on what parents can expect of the stillbirth process, health professional's timely advice and environmental arrangements can be more quality based and culturally adapted.

\section{References}

1. Lasker JN, Toedter LJ (1994) Satisfaction with hospital care and interventions after pregnancy loss. Death Studies 18: 41-64.

2. Leon IG (1992) Perinatal loss. A critique of current hospital practices. Clinical Pediatrics 31: 366-374.

3. Lewis E (1979) Mourning by the family after a stillbirth or neonatal death. Archives of Disease in Childhood 54: 303-306.

4. National Institute for Health and Clinical Excellence, 2007. Antenatal and Postnatal Mental Health-Clinical Management and Service Guidance.

5. Radestad I, Nordin C, Steineck G, Sjogren B (1996) Stillbirth is no longer managed as a nonevent: a nationwide study in Sweden. Birth 23: 209-215.

6. Radestad I (2001) Stillbirth: care and long-term psychological effects. British Journal of Midwifery 9: 474-480.

7. Weiss M (1987) Care and support of women who have experienced a stillbirth. Midwives Chronicle 100: 233-234. 